OPEN ACCESS

Edited by:

Moisés Canle,

University of A Coruña, Spain

Reviewed by:

Marie-Christine Scherrmann, Université Paris-Saclay, France

Zhuohua Sun,

Beijing Forestry University, China Luis Sarandeses,

University of A Coruña, Spain

*Correspondence:

Rakesh Kumar Sharma rksharmagreenchem@hotmail.com

Specialty section:

This article was submitted to Green and Sustainable Chemistry,

a section of the journal

Frontiers in Chemistry

Received: 10 September 2021 Accepted: 13 December 2021 Published: 17 January 2022

Citation:

Yadav M, Srivastava A, Gaur R, Gupta R, Arora $G$ and Sharma RK (2022) An Efficient and Sustainable Approach to Decarboxylative CrossCoupling Using Silica Coated Magnetic Copper Nanocatalyst for the Synthesis of Internal Alkynes.

Front. Chem. 9:773855 doi: 10.3389/fchem.2021.773855

\section{An Efficient and Sustainable Approach to Decarboxylative Cross-Coupling Using Silica Coated Magnetic Copper Nanocatalyst for the Synthesis of Internal Alkynes}

\author{
Manavi Yadav ${ }^{1,2}$, Anju Srivastava ${ }^{2}$, Rashmi Gaur ${ }^{1}$, Radhika Gupta ${ }^{1}$, Gunjan Arora ${ }^{1}$ and \\ Rakesh Kumar Sharma ${ }^{1 *}$ \\ ${ }^{1}$ Green Chemistry Network Centre, Department of Chemistry, University of Delhi, New Delhi, India, ${ }^{2}$ Department of Chemistry, \\ Hindu College, University of Delhi, Delhi, India
}

A highly efficient magnetically separable copper nanocatalyst has been developed for decarboxylative cross-coupling reaction for the alkynylation of haloarenes using alkynoic acid as a reaction partner. The chemical nature, morphology, size, and magnetic properties of the prepared nanocatalyst were studied by SEM, TEM, EDS, FT-IR, VSM, and ICP techniques. Remarkably, this catalyst represents the first successful copper based heterogeneous system for this type of coupling that provides a low-cost, stable, and environmentally friendly magnetically recoverable entity that can be re-used for seven consecutive runs without appreciable loss in its catalytic performance.

Keywords: magnetic, copper, nanocatalyst, decarboxylative cross-coupling, heterogeneous catalyst

\section{INTRODUCTION}

Transition metal catalyzed cross-coupling reactions for the construction of carbon-carbon (C-C) bond are amongst the most powerful and efficient strategy for synthesizing essential organic compounds including bioactive compounds, natural products, and polymeric materials (Sonogashira, 2002; Tykwinski, 2003; Jutand, 2004). For this, various traditional crosscoupling reactions have been employed, however, these methods utilize organometallic compounds that bear $\mathrm{Mg}, \mathrm{Al}, \mathrm{Zn}, \mathrm{Sn}, \mathrm{B}$, and $\mathrm{Si}$, which create problem of metal contamination in the product. On comparison with the well-established cross-coupling reactions, decarboxylative cross-coupling reaction offers several benefits since it involves readily available carboxylic acid derivatives that do not encounter storage and handling difficulties and releases less-toxic carbon dioxide as the by-product that reduces the waste treatment costs. (Moon et al., 2008a; Moon et al., 2008b; Kim and Lee, 2009; Park et al., 2010; Zhang et al., 2010; Zhao et al., 2010; Li et al., 2011; Pan et al., 2011; Qu et al., 2011; Li et al., 2012; Tartaggia et al., 2012; Park and Lee, 2013; Reddy et al., 2013; Lee et al., 2016; Maaliki et al., 2016).

Due to the wide occurrence of alkyne moiety in natural products, pharmaceuticals, and molecular materials, enormous efforts have been devoted towards the synthesis of arylalkynes and conjugated enynes.(Brandsma, 2003; Negishi and Anastasia, 2003; Stang and Tykwinski, 2006; Chinchilla and Nájera, 2007). Of all, the Sonogashira coupling superseded all the traditional methods for synthesizing internal alkynes from nucleophilic terminal acetylenes. (Nicolaou et al., 2005; 


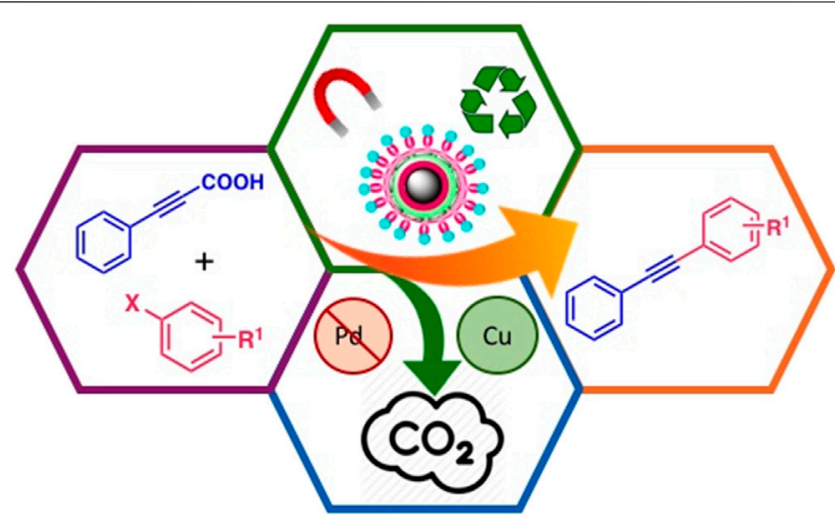

GRAPHICAL ABSTRACT | Magnetic Silica core-shell copper nanocatalyst in the decarboxylative coupling for the synthesis of alkynes.

Stang, 2008). However, the formation of homo-coupled byproduct and volatile liquid nature of terminal alkynes, are the major drawbacks which limit their utility in industrial applications. (Kolarovic et al., 2011). Therefore, the straightforward synthesis of arylalkynes with some other readily available substrates remained a practical challenge for many years. In recent times, decarboxylative cross-coupling of alkynoic acids with haloarenes emerged as an attractive and practical solution. (Siemsen et al., 2000; Das et al., 2005; Feng and Loh, 2010; Jia and Jiao, 2010; Park et al., 2011).

To date, a number of homogeneous catalytic systems using palladium, copper and nickel catalysts have been developed for the decarboxylative coupling of alkynoic acids with haloarenes. (Edwin Raja et al., 2016). However, most of them employ toxic phosphine ligands, and costly additives that are also air and moisture sensitive.

Despite tremendous success in the development of this methodology, till now, only few Pd-based heterogeneous catalysts have been reported for this reaction. (Pyo et al., 2013; Reddy et al., 2016). Moreover, these protocols have common problems associated with the palladium based catalysts, such as their high cost that limit their industrial applications. Nonetheless, exploring cost-effective methods to prepare highly stable, efficient, and recyclable heterogeneous catalysts still remain a challenging task in this field.

Therefore, employment of an economic and greener first row transition metal heterogenized catalyst is highly desirable. In this respect, copper-catalyzed systems have gained tremendous progress due to their economic attractiveness and good functional group tolerance (Ley and Thomas, 2003; Evano et al., 2008; Monnier and Taillefer, 2009). However, copper mediated synthesis of internal alkynes via decarboxylative coupling reaction is still less explored (Shang et al., 2009).

In line with current challenges arising from the demands of industrial and fine chemistry, an ideal catalyst should not only possess high activity and selectivity towards the targeted products but should be stable, environmental friendly, recyclable, and must be easy to recover from the reaction mixture. In view of these requirements, silica coated magnetic nanoparticles (SMNPs) appear to be an ideal solution as solid supports due to their chemical inertness, robustness, easy magnetic recovery, recyclability, and environmentally benign nature (Rossi et al., 2014; Wang and Astruc, 2014; Sharma et al., 2016b).

Thus, in continuation of our ongoing research work on the development of nanocatalysts, and their applications in various organic transformations, (Sharma et al., 2015a; Sharma et al., 2015b; Sharma et al., 2016a; Sharma et al., 2016c; Arora et al., 2017; Gupta et al., 2017; Sharma et al., 2018), we herein describe the fabrication of a novel copper nanocatalyst with modified silica magnetic core-shell support for efficiently catalyzing decarboxylative coupling of alkynoic acid with haloarenes.

\section{MATERIALS AND METHODS}

3-aminopropyltriethoxysilane (APTES), tetraethoxyorthosilicate (TEOS), and 4, 5-diazafluoren-9-one were procured from Sigma Aldrich. Ferric sulphate hydrate and ferrous sulphate heptahydrate were obtained from Sisco Research Laboratory (SRL). copper(I) iodide, $\mathrm{Cs}_{2} \mathrm{CO}_{3}$, and toluene were purchased from Merck.

The prepared nanocatalyst was characterized using several techniques. X-ray diffraction (XRD) patterns were obtained from a D8 Discover Bruker AXS (Karlsruhe, Bundesland, Germany) diffractometer in the $2 \theta$ range of $10-80$. For uniformity and morphology HR-TEM, FEI TECNAIF 30 transmission electron microscope with HAADF detector was used and operated at $300 \mathrm{kV}$. In order to study the chemical composition of the catalyst, X-ray energy dispersive spectroscopy (EDS) was carried out using Ametek EDAX system. Carl Zeiss India scanning electron microscope was used to investigate for analyzing the structural properties of prepared nanocomposites. EV-9, Microsense, ADE vibrating sample magnetometer was used to conduct magnetization measurements. The Fourier transform infrared spectra (FT-IR) of NPs were collected at every stage of synthesis using PerkinElmer Spectrum 2000. For the estimation of amount of copper in the catalyst and in the supernatant inductively coupled plasma (ICP) of PerkinElmer Optima 2100 DV was used. The products were confirmed by making use of Agilent gas chromatography- 


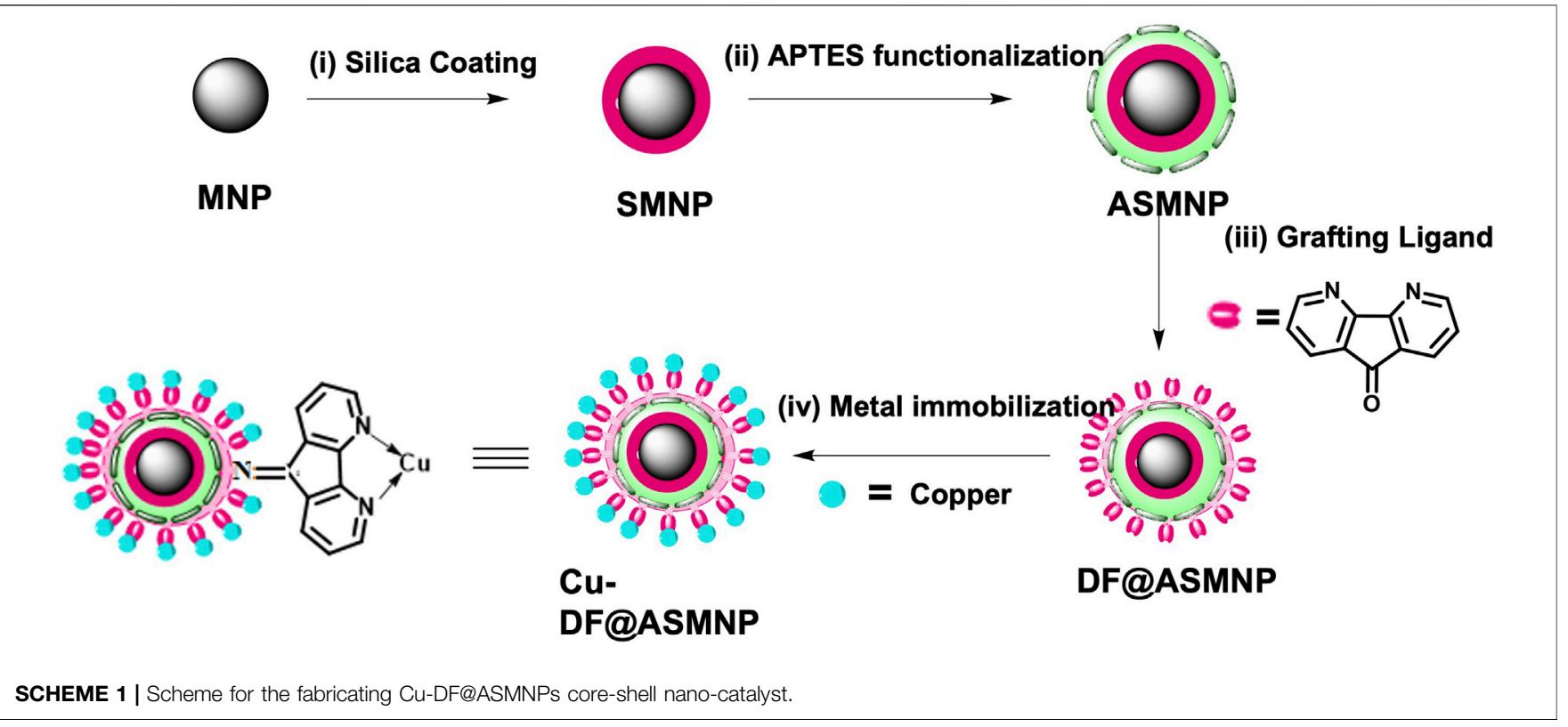

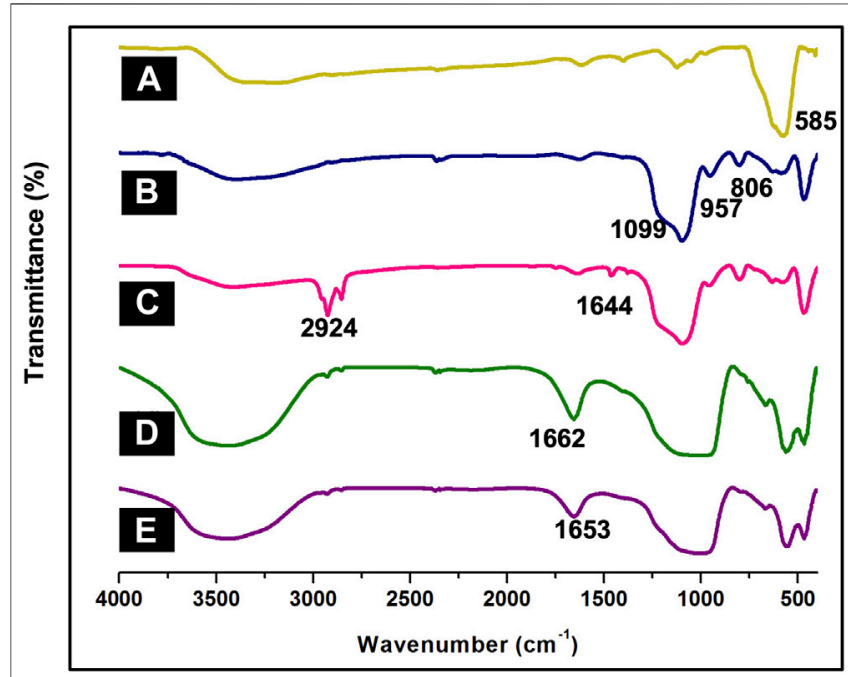

FIGURE 1 | FT-IR spectra of (A) MNPs, (B) SMNPs, (C) ASMNPs, (D) DF@ASMNPs, and (E) Cu-DF@ASMNPs.

mass spectrometer with a HP-5MS 5\% phenyl methyl siloxane capillary column $(30.0 \mathrm{~m} \times 0.25 \mathrm{~mm} \times 0.25 \mu \mathrm{m})$ using helium as a carrier gas.

\subsection{Synthesis of Cu-DF@ASMNPs}

Firstly, MNPs were synthesized by co-precipitation technique. (Polshettiwar and Varma, 2009). For this, ferric sulphate $(6.0 \mathrm{~g})$ and ferrous sulphate ( $4.2 \mathrm{~g}$ ) were dissolved in $250 \mathrm{ml}$ distilled water and stirred at $60 \mathrm{C}$. To the obtained orange solution, $25 \%$ of $\mathrm{NH}_{4} \mathrm{OH}(15 \mathrm{ml})$ was added dropwise and the solution was stirred vigorously for $30 \mathrm{~min}$. The obtained black precipitates of MNPs were separated with external magnet and thoroughly washed with water and ethanol and finally dried under vacuum.

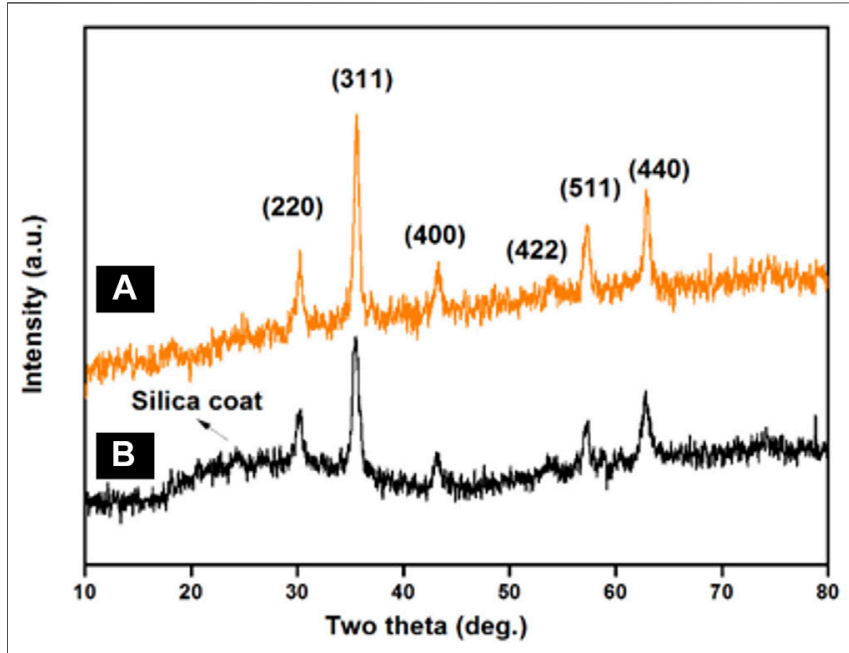

FIGURE $2 \mid$ XRD patterns of (A) MNPs and (B) SMNPs.

On to this, silica coating was performed via sol-gel approach to form SMNPs, (Zhang et al., 2011), which was further functionalized with the $\mathrm{NH}_{2}$ linker, APTES. For silica coating, $0.5 \mathrm{~g}$ of MNPs were dissolved in $2.2 \mathrm{ml}$ of $0.1 \mathrm{M} \mathrm{HCl}$ and dispersed in $200 \mathrm{ml}$ ethanol and $50 \mathrm{ml}$ water under sonication. Further, $5 \mathrm{ml}$ $\mathrm{NH}_{4} \mathrm{OH}$ was added followed by addition of $1 \mathrm{ml}$ of TEOS under constant stirring at $60 \mathrm{C}$ for $6 \mathrm{~h}$ to give SMNPs. These SMNPs were washed with ethanol and water. The functionalization with $\mathrm{NH}_{2}$ linker was performed by adding $0.5 \mathrm{ml}$ of APTES to the dispersed solution of $0.1 \mathrm{~g}$ of SMNPs in $100 \mathrm{ml}$ of ethanol under constant stirring at $50 \mathrm{C}$ for $6 \mathrm{~h} .1 \mathrm{~g}$ of resulting APTES functionalized SMNPs (ASMNPs) were further reacted with a $0.75 \mathrm{mmol}$ of bidentate ligand, 4, 5-diazafluoren-9-one (DF) in acetone at 


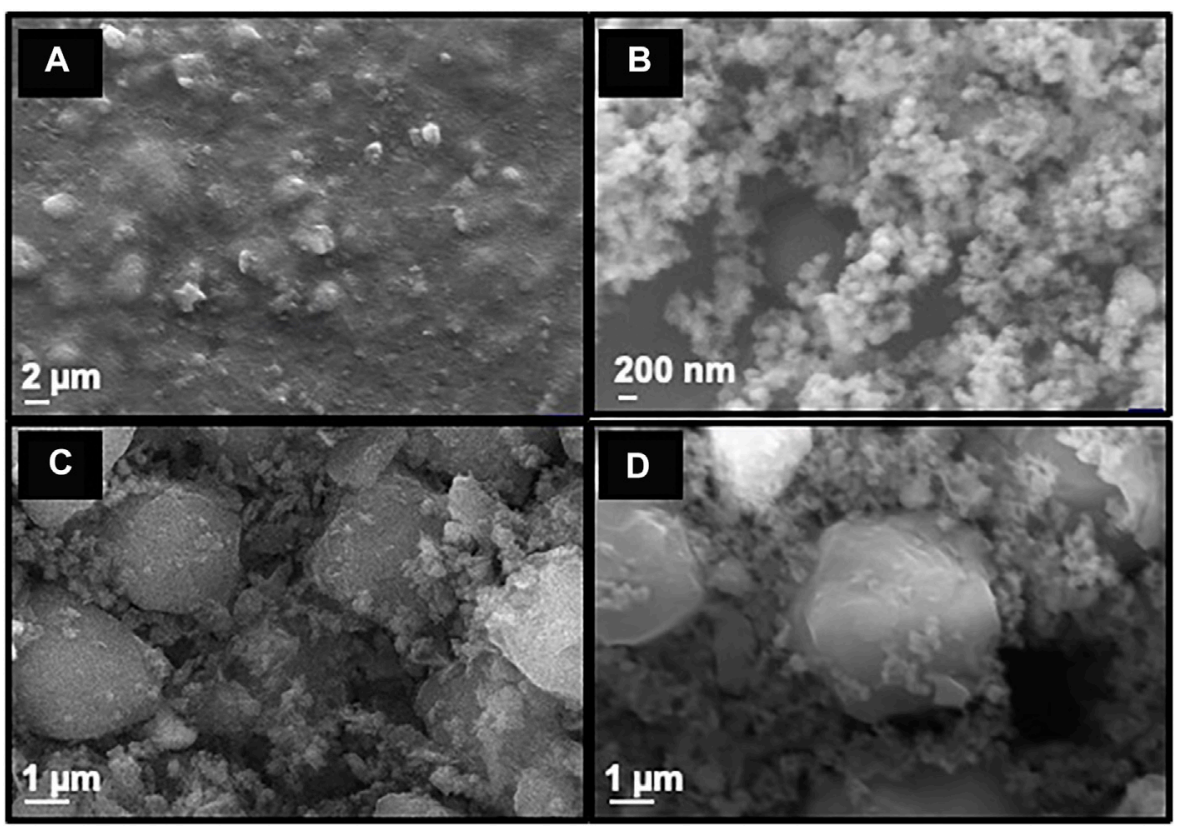

FIGURE 3 | SEM images of (A) MNPs, (B) SMNPs, (C) Fresh Cu-DF@ASMNPs and (D) Recovered Cu-DF@ASMNPs.

$70^{\circ} \mathrm{C}$ for $3 \mathrm{~h}$. The resulting DF@ASMNPs were washed with ethanol and dried under vacuum. To $1 \mathrm{~g}$ of DF@ASMNPs, $1.5 \mathrm{mmol}$ of copper iodide was added and the solution was stirred for $3 \mathrm{~h}$ using acetone as solvent. The resulting nanocatalyst was magnetically recovered and thoroughly washed with deionized water and dried under vacuum to obtain the final catalyst Cu-DF@ASMNPs. (Scheme 1).

\subsection{Cu-DF@ASMNPs Catalyzed Internal Alkynes Synthesis}

For this, $10 \mathrm{ml}$ of round bottom flask was flushed with nitrogen and to this, haloarene $(0.5 \mathrm{mmol})$, alkynoic acid $(0.6 \mathrm{mmol}), \mathrm{Cu}-$ DF@ASMNPs $(25 \mathrm{mg})$, and $\mathrm{Cs}_{2} \mathrm{CO}_{3}(1.0 \mathrm{mmol})$ were added. Again, nitrogen was flushed, and toluene $(2 \mathrm{ml})$ was added at room temperature. The temperature was raised to $100^{\circ} \mathrm{C}$ with continuous stirring for $12 \mathrm{~h}$. On bringing to room temperature, the mixture was extracted with ethyl acetate. The reaction was monitored and analyzed by GC-MS.

\section{RESULTS AND DISCUSSION}

\subsection{Characterization of Catalyst 3.1.1 FT-IR Spectroscopy}

In order to analyze parent nanocomposite and its further functionalization, FT-IR spectroscopy was employed. A band was observed at $585 \mathrm{~cm}^{-1}$ in the IR-spectrum of MNPs depicting the Fe-O stretching absorption (Figure 1A). (Zhu et al., 2011) The intensity of this band reduced on silica-coating with the appearance of three new sharp bands in the region of 806, 957 and $1,099 \mathrm{~cm}^{-1}$, corresponding to the symmetric $\mathrm{Si}-\mathrm{O}-\mathrm{Si}$, symmetric $\mathrm{Si}-\mathrm{O}(\mathrm{H})$ and asymmetric $\mathrm{Si}-\mathrm{O}-\mathrm{Si}$ stretching vibrations respectively (Figure 1B) (Kooti and Afshari, 2012) Further functionalization of SMNPs with APTES resulted in absorption at $2,924 \mathrm{~cm}^{-1}$ and $1,644 \mathrm{~cm}^{-1}$, which corresponds to $\mathrm{CH}_{2}$ and $\mathrm{NH}_{2}$ from aminopropyl moiety of APTES (Figure 1C) (Yamaura et al., 2004) The immobilization of ligand DF onto ASMNPs was confirmed by the band at $1,662 \mathrm{~cm}^{-1}$ accredited to $\mathrm{C}=\mathrm{N}$ stretching frequency (Figure 1D) and to this, metal was immobilized using $\mathrm{CuI}$ which shifted the prominent band at $1,662 \mathrm{~cm}^{-1}$ to a lower wavenumber indicating strong metalligand interaction (Figure 1E). (Masteri-Farahani and Tayyebi, 2011; Esmaeilpour et al., 2012).

\subsubsection{XRD Studies}

To assess the crystalline nature of synthesized MNPs and SMNPs, powder X-Ray diffraction measurements were carried out. For MNPs (Figure 2A), six characteristic peaks were observed at 2 $\theta$ : $30.366^{\circ}, 35.663^{\circ}, 43.024^{\circ}, 53.6^{\circ}, 57.299^{\circ}$, and $62.865^{\circ}$ corresponding to the (220), (311), (400), (422), (511) and (440) crystallographic faces of magnetite (Abu-Reziq and Alper, 2012). These peaks were in accordance with the standard XRD data provided by the Joint Committee on Powder Diffraction Standards (JCPDS) card number 19-0,629 and is ascribed to inverse cubic spinel $\mathrm{Fe}_{3} \mathrm{O}_{4}$ crystal (Abu-Reziq et al., 2006). The average crystallite size of the MNPs was calculated by the Scherrer equation $\left\{\mathrm{D}_{\mathrm{hkl}}=\mathrm{K} \lambda /\left(/\left(\beta_{\mathrm{hkl}} \cos \theta\right)\right\}\right.$, where $D_{h k l}$ represents the size of the axis parallel to the (hkl) plane, $\mathrm{k}$ is a constant with a common value of 0.89 for spherical particles, $\lambda$ is the wavelength of radiation, $\beta_{\mathrm{hkl}}$ is the full-width at half-maximum (FWHM) in radians, and $\theta$ is the diffraction angle. The mean crystallite size was found to be $\sim 10.6 \mathrm{~nm}$ for the (311) reflection. Besides these six diffraction peaks, a weak 

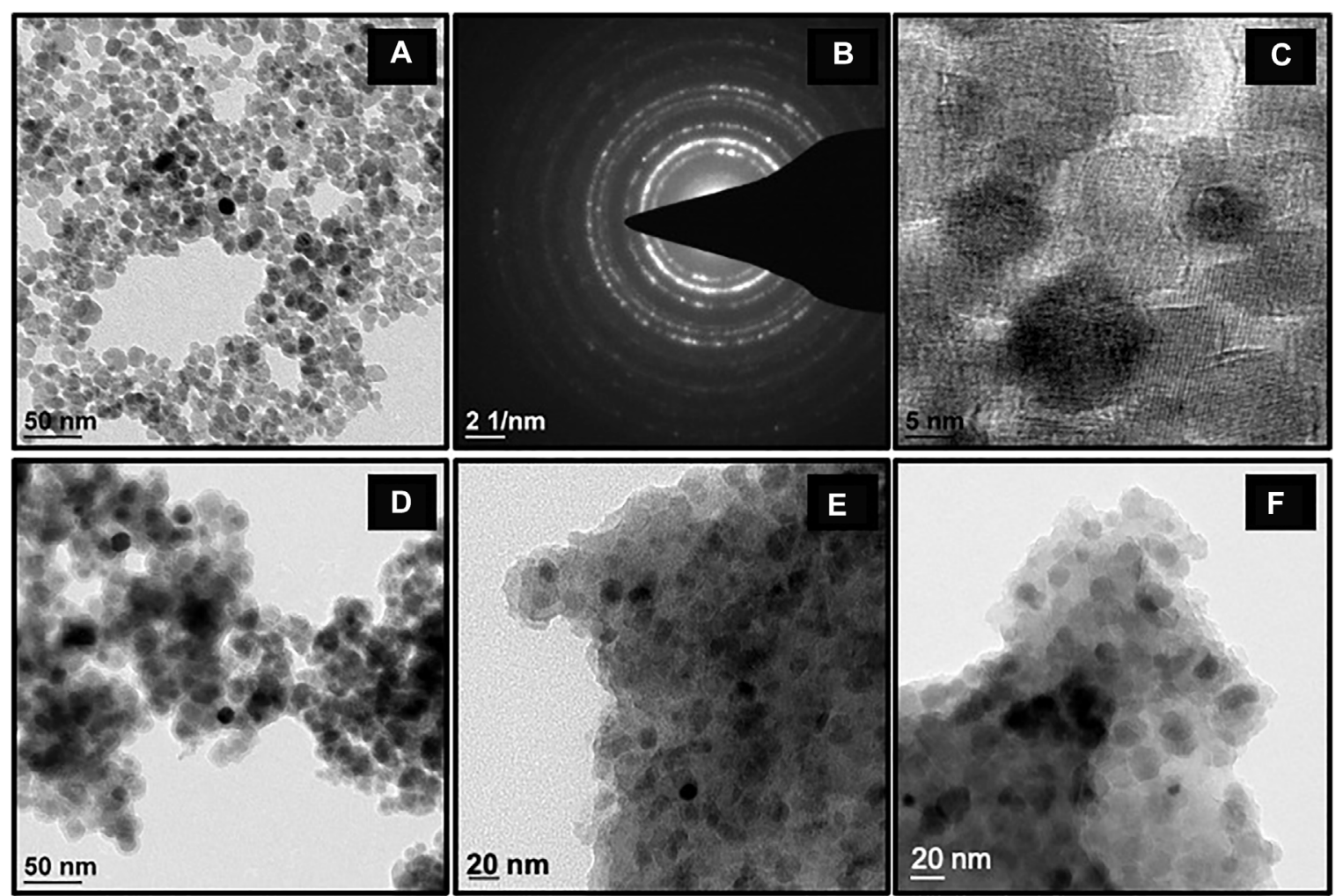

FIGURE 4 | TEM images of the nanoparticles obtained at different stages of synthesis: (A) MNPs, (B) SAED pattern of MNPs, (C) HR-TEM image of MNPs, (D) SMNPs, (E) Fresh Cu-DF@ASMNPs, and (F) Recovered Cu-DF@ASMNPs.

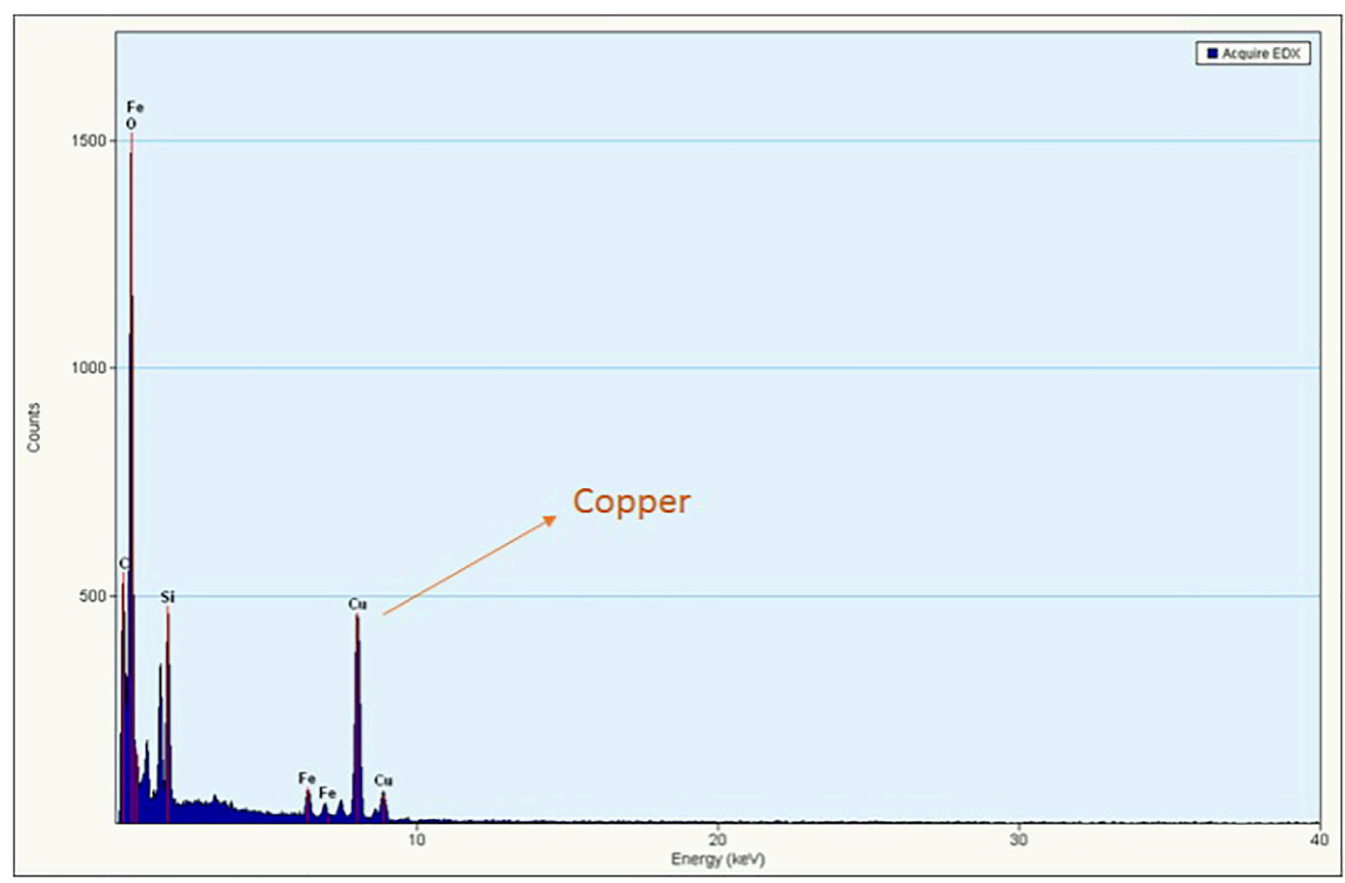

FIGURE 5 | EDS pattern of Cu-DF@ASMNPs. 


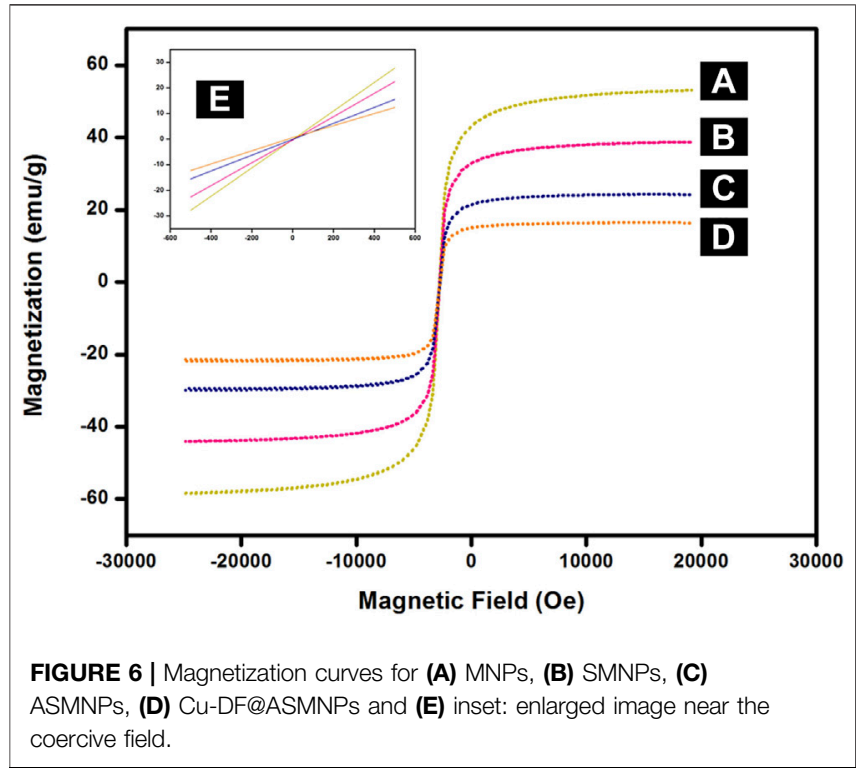

broad hump at $2 \theta=20-24^{\circ}$ is observed in the XRD pattern of SMNPs showed in Figure 2B, which is attributed to amorphous silica (Zhang et al., 2012).

\subsubsection{SEM Analysis}

To investigate the topography of the synthesized nanoparticles, scanning electron microscopic (SEM) analysis was performed and it was found that the smooth surface of MNP (Figure 3A) turns spongy on silica coating (Figure 3B). The spherical morphology of the final Cu-DF@ASMNPs catalyst was seen with slight agglomeration and appears the same as that of
SMNP (Figure 3C). This suggested that the surface modification methods did not alter the morphology of the nanocatalyst. Besides this, the SEM image of the recovered catalyst (Figure 3D) also indicates that the reaction did not affect the morphology of the catalyst.

\subsubsection{TEM Analysis}

TEM studies were performed to study the morphological changes of the synthesized nanomaterials, Figure 4A depicts that MNPs are polydisperse in nature and display slight agglomeration (Wang et al., 2010; Wang et al., 2013). An array of bright diffraction rings was observed in the selected area electron diffraction pattern (SAED) (Figure 4B) which confirmed the crystalline nature of these nanocomposites and also in accordance with the resultant XRD pattern. The average interplanar distance of the MNPs was measured from a high-resolution transmission electron microscopy (HR-TEM) image and was found to be $\sim 0.20 \mathrm{~nm}$, which correlates with the (311) plane of inverse spinel $\mathrm{Fe}_{3} \mathrm{O}_{4}$ structure (Figure 4C). A dark core-shell of MNP, with an almost uniform silica coat of 4-5 nm thickness, was observed in the TEM image of SMNP (Figure 4D). TEM images of final catalyst and recovered catalyst are shown in Figure 4E and Figure 4F respectively, which further confirm that the structural morphology remain unchanged after the coupling reaction. In order to find the average particle size of MNPs, 52 colloidal aggregates were analyzed and it was found to be in the range of 10-11 nm (Supplementary Figure S1) which is in well accordance with the XRD results.

\subsubsection{EDS Analysis and Metal Content Determination}

Energy dispersive X-ray analysis was performed to detect the composition of the synthesized nanocomposites, and the EDS

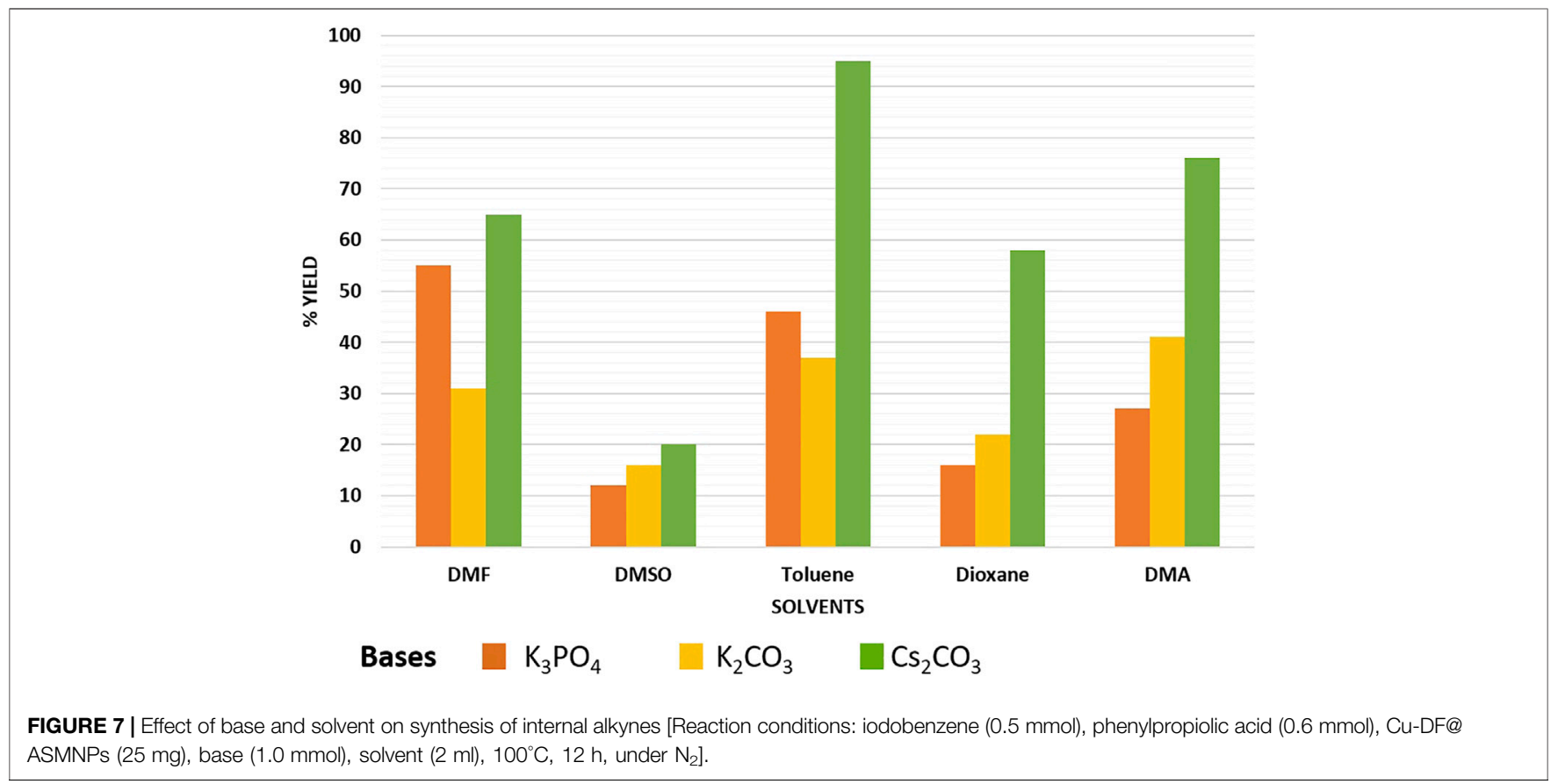


Yadav et al.

Copper Nanocatalyst for Decarboxylative Coupling

TABLE 1 | Scope of catalytic performance of the Cu-DF@ASMNP for synthesizing internal alkyne ${ }^{\text {a }}$.

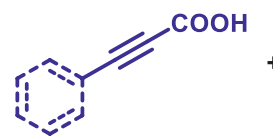

1

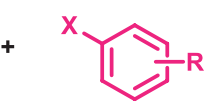

2

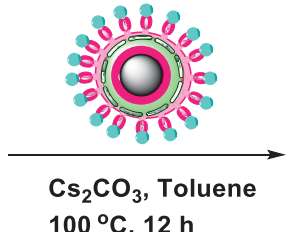

$100^{\circ} \mathrm{C}, 12 \mathrm{~h}$

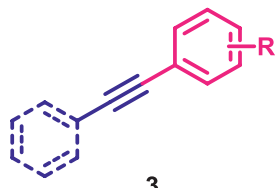

3

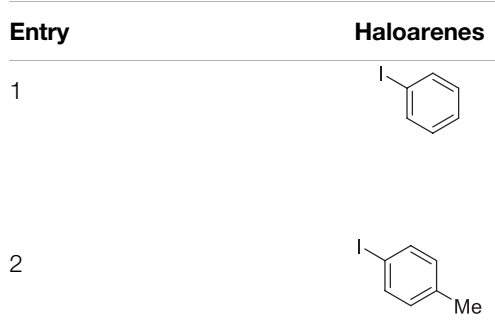

$3^{d}$

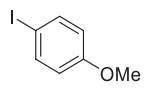

4

5

6
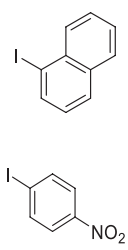

7

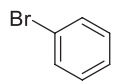

8

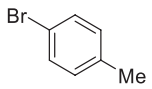

9

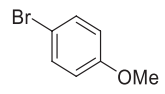

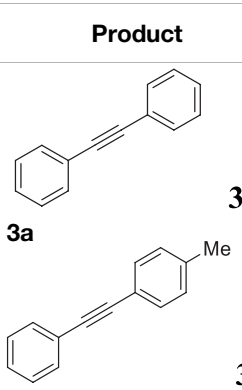

Bb

Bb

$88 / 82^{e}$

110

Bc

$3 c$

$94 / 90^{\mathrm{e}}$

118

95

119

Bd

Bd

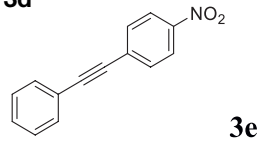

$3 e$

$89 / 85^{e}$

111

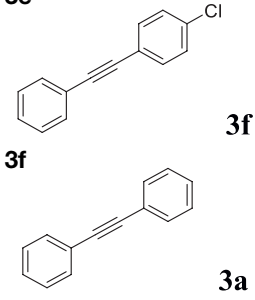

100
$3 a$

86

108

$3 \mathbf{b}$

Bb

80

84

105

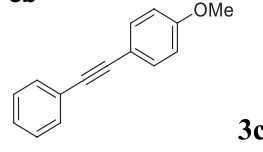

Bc

(Continued on following page)

Frontiers in Chemistry | www.frontiersin.org

7

January 2022 | Volume 9 | Article 773855 
TABLE 1 | (Continued) Scope of catalytic performance of the Cu-DF@ASMNP for synthesizing internal alkynes ${ }^{\text {. }}$

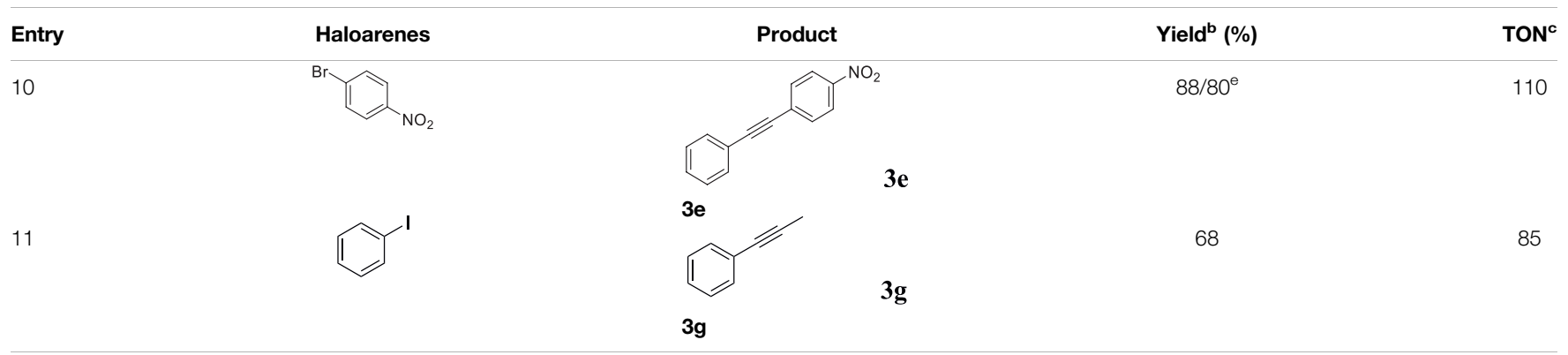

${ }^{a}$ Reaction conditions: Haloarene ( $\left.0.5 \mathrm{mmol}\right)$, alkynoic acid (0.6 mmol), Cu-DF@ASMNP (25 mg), $\mathrm{Cs}_{2} \mathrm{CO}_{3}(1.0 \mathrm{mmol})$, toluene (2 ml), $100^{\circ} \mathrm{C}, 12 \mathrm{~h}, \mathrm{under} \mathrm{N}_{2}$.

${ }^{b} \mathrm{GC}-\mathrm{MS}$, yield.

${ }^{c}$ TON , Calculated using the $0.3217 \mathrm{mmolg}^{-1}$, copper.

${ }^{\mathrm{e}}$ Isolated yield.

${ }^{d}$ Reaction was performed on large scale; Haloarene (5 mmol), alkynoic acid (6 mmol), Cu-DF@ASMNP (0.25 g), Cs $\mathrm{CO}_{3}(10.0 \mathrm{mmol})$, toluene (10 ml), $100^{\circ} \mathrm{C}, 12 \mathrm{~h}, \mathrm{under} \mathrm{N}_{2}$.

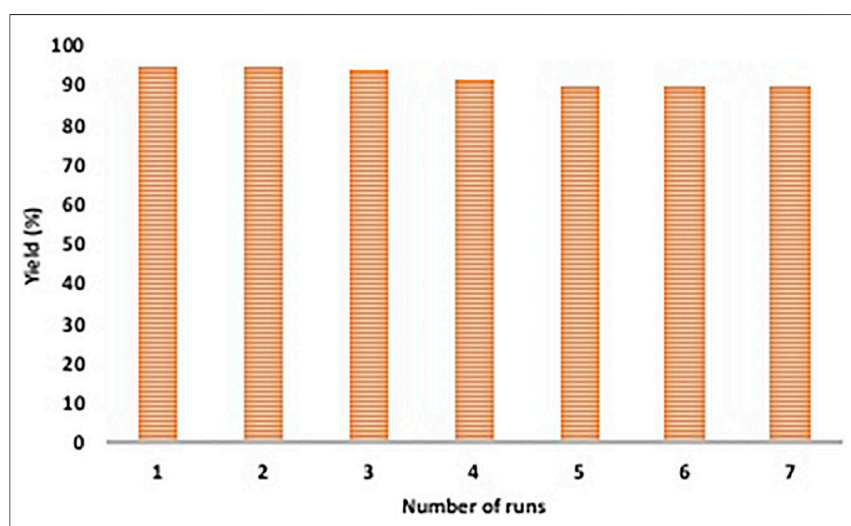

FIGURE 8 | Catalyst recycling test for the synthesis of internal alkynes.

spectrum displayed well-defined peaks of copper, silicon and iron (Figure 5) that substantiate the effective grafting of copper on the Cu-DF@ASMNPs. Moreover, to determine the amount of copper present in the final catalyst, ICP analysis was conducted and the metal loading was found to be $0.3217 \mathrm{mmolg}^{-1}$.

\subsubsection{VSM Analysis}

The field-dependent magnetization measurement of synthesized nanocomposites is provided in Figure 6. The superparamagnetic behaviour of these nanoparticles was confirmed by their magnetization curves which display no hysteresis at room temperature. This was further corroborated by the inset in Figure 6 where both coercivity and remanence were negligible in the absence of an externally applied magnetic field. The saturation magnetization value of MNPs, SMNPs, ASMNPs, and Cu-DF@ASMNPs were found to be $59 \mathrm{emu} \mathrm{g}^{-1}$, $40 \mathrm{emu} \mathrm{g}^{-1}, 29 \mathrm{emu} \mathrm{g}^{-1}$, and $19 \mathrm{emu} \mathrm{g}^{-1}$ respectively. This decrease in the $M_{s}$ value is due to the non-magnetic nature of the functionalizing groups. (Hu et al., 2005; Digigow et al., 2014). Despite of lower value of magnetization, the net magnetism of $\mathrm{Cu}-\mathrm{DF} @ \mathrm{ASMNPs}$ was high enough for its effortless removal via an external magnet.

\subsection{Catalytic Studies}

\subsubsection{Optimization of the Reaction Conditions}

In order to test the efficacy of the prepared nano-catalyst, $\mathrm{Cu}$ DF@ASMNPs and to discover the optimal reaction conditions, phenylpropiolic acid $(0.6 \mathrm{mmol})$ and iodobenzene $(0.5 \mathrm{mmol})$ were selected as the coupling partners. For the optimization of decarboxylative cross-coupling reaction, reaction parameters like solvent, base and catalytic amount were assessed. Figure 7 represent several combinations of base and solvent, and out of them highest yield was obtained when the base was $\mathrm{Cs}_{2} \mathrm{CO}_{3}$ $(1 \mathrm{mmol})$, and toluene $(2 \mathrm{ml})$ was the solvent. For the determination of the optimal catalytic amount, a blank test was carried out, where no significant yield was obtained. Although, the reaction gave product with $10 \mathrm{mg}$ of catalyst and on increasing the amount of catalyst, significant increase in yield of the product was noticed. However, no noticeable increase in the product yield was found when $30 \mathrm{mg}$ of catalyst was used and the best yield was achieved with $25 \mathrm{mg}$ of catalyst (Supplementary Table S1). Also, the reaction was performed under diverse range of temperatures while keeping other parameters constant and $100 \mathrm{C}$ was found to be the optimum temperature to carry out the coupling with $25 \mathrm{mg}$ of synthesized catalyst (Supplementary Figure S2). Therefore, all the reactions were performed using toluene as the reaction solvent, $\mathrm{Cs}_{2} \mathrm{CO}_{3}$ as the base for $12 \mathrm{~h}$ at $100 \mathrm{C}$ in the presence of $25 \mathrm{mg}$ of $\mathrm{Cu}-\mathrm{DF} @ \mathrm{ASMNPs}$ under $\mathrm{N}_{2}$ atmosphere.

\subsubsection{Catalytic Activity of Cu-DF@ASMNPs Catalyst for Decarboxylative Cross-Coupling of Alkynoic Acids With Haloarenes}

To demonstrate the efficiency of this method, various haloarenes including iodo and bromo derivatives were coupled with phenylpropiolic acid using the optimized reaction conditions (Table 1 ). To check the scope of this reaction, we initially examined a variety of iodoarenes possessing both activating and deactivating groups including methoxy, methyl, naphthyl, nitro, and chloro. It was observed that the reaction went smoothly for both electron donating and withdrawing groups on the 


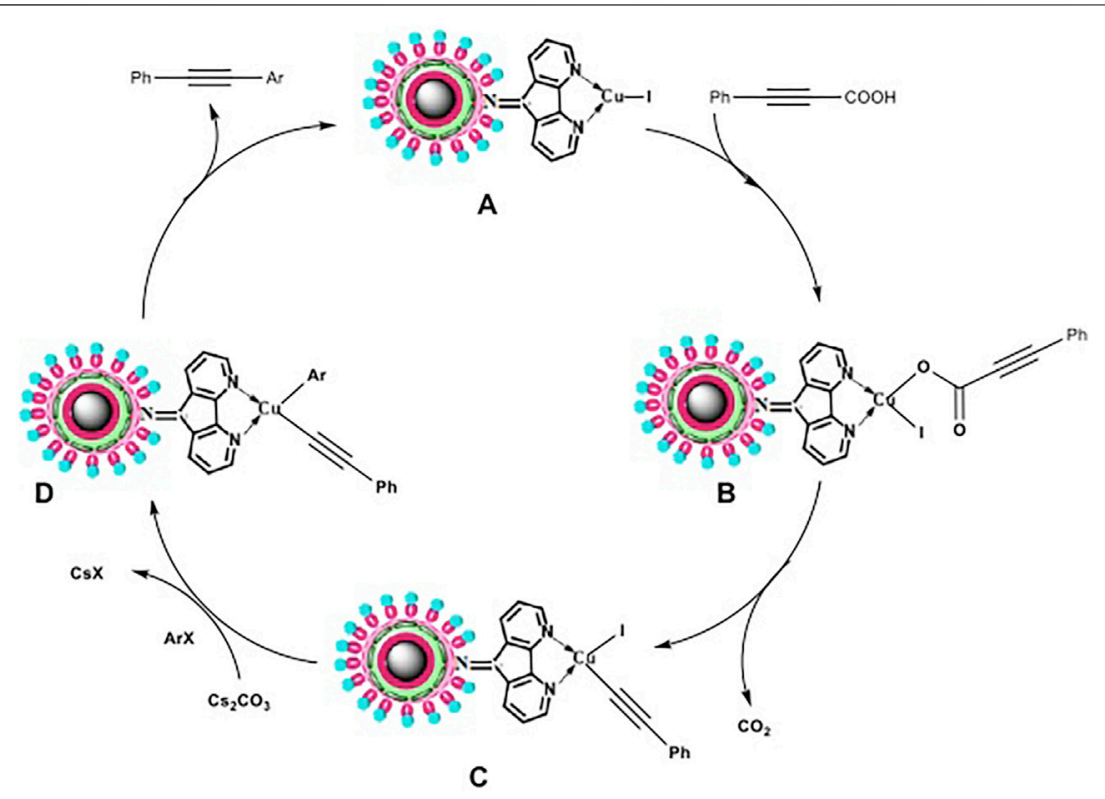

FIGURE 9 | Proposed reaction mechanism.

TABLE 2 | A comparison of the obtained results with previous published work for the synthesis of internal alkynes.

S.No

\section{Acid}<smiles>O=C(O)C#Cc1ccccc1</smiles>

2<smiles>O=C(O)C#Cc1ccccc1</smiles>

3<smiles>O=C(O)C#Cc1ccccc1</smiles><smiles>O=C(O)C#Cc1ccccc1</smiles>

5<smiles>O=C(O)C#CC=[Pb]</smiles>

6<smiles>O=C(O)C#Cc1ccccc1</smiles>

\section{Coupling partner}

$\mathrm{Br}$<smiles>Cc1ccc(Br)cc1</smiles>

tBu<smiles>Ic1cccc2ccccc12</smiles><smiles>[X]c1ccccc1</smiles>

$\mathrm{Pd}(\mathrm{OAc})_{2}$

Palladacycle (1 mol\%)

$\mathrm{Cl}$<smiles>c1ccccc1</smiles><smiles>Ic1ccccc1</smiles>

$\mathrm{Pd}\left(\mathrm{PPh}_{3}\right)_{2} \mathrm{Cl}_{2}$ (1 $\left.\mathrm{mol} \%\right)$

$2 \mathrm{~mol} \%$ of dppb, DMSO, $110^{\circ} \mathrm{C}, 2 \mathrm{~h}$<smiles>Cc1ccc(Br)cc1</smiles>

$\left[\mathrm{PdCl}(\text { allyl) }]_{2}\right.$ (2.5 mol\%)
$\mathrm{PPh}_{3}$ (16 mol\%), $\mathrm{Ag}_{2} \mathrm{O}$ (1-3 equiv), Lil (3-6 equiv), DMF

XPhos, $\mathrm{Cs}_{2} \mathrm{CO}_{3}, \mathrm{THF}, 80^{\circ} \mathrm{C}$

Xphos (4 mol\%), $\mathrm{K}_{2} \mathrm{CO}_{3}$ (2 equiv), xylene/ $\mathrm{H}_{2} \mathrm{O} 120^{\circ} \mathrm{C}, 3 \mathrm{~h}$

SPhos (7.5 mol\%), TBAF (3.0 equiv), NMP/ $\mathrm{H}_{2} \mathrm{O}, 80^{\circ} \mathrm{C}, 14 \mathrm{~h}$
96

Moon et al.

(2008a)

\section{Ref}

Moon et al. (2008b)

Kim and Lee, (2009)

70-95 Zhang et al. (2010) 
TABLE 2 | (Continued) A comparison of the obtained results with previous published work for the synthesis of internal alkynes.

S.No

Acid

Coupling partner

Catalyst

Conditions

Yield Ref

(\%)

1,10-Phen (10 mol\%), $\mathrm{Cs}_{2} \mathrm{CO}_{3}$ (1.5 equiv)

DMF, $130^{\circ} \mathrm{C}, 24 \mathrm{~h}$

99 Zhao et al. (2010)<smiles>O=C(O)C#Cc1ccccc1</smiles><smiles>Ic1ccccc1</smiles>

Cul (10 mol\%)

$>\quad C u l(2 \mathrm{~mol} \%)$

$\mathrm{PPh}_{3}$ (4 mol\%), $\mathrm{K}_{2} \mathrm{CO}_{3}$ (3 equiv), DMSO/

$\mathrm{H}_{2} \mathrm{O} 100^{\circ} \mathrm{C}, 24 \mathrm{~h}$, under argon

97

Li et al. (2012)<smiles>O=C(O)C#Cc1ccccc1</smiles><smiles>C=CC=CC</smiles>

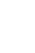

$>\quad \mathrm{Cul}(0.5 \mathrm{~mol} \%) / \mathrm{Fe}$ (acac) $)_{3}$ ) (1 equiv)

$\mathrm{K}_{3} \mathrm{PO}_{4}$ (2 equiv), DMSO (2 ml), $140^{\circ} \mathrm{C}$,<smiles>O=C(O)C#Cc1ccccc1</smiles>
24-48 h, under argon<smiles>O=C(O)C=Cc1ccccc1</smiles><smiles>Ic1ccccc1</smiles>

11<smiles>O=C(O)C#Cc1ccccc1</smiles>

$12^{\mathrm{a}}$<smiles>O=C(O)C#Cc1ccccc1</smiles>

$13^{a}$<smiles>O=C(O)C#Cc1ccccc1</smiles>

$14^{\mathrm{a}}$<smiles>O=C(O)C#Cc1ccccc1</smiles>

$(\mathrm{EtO})_{3} \mathrm{~S}$<smiles>[SiH3]c1ccccc1</smiles>

$\mathrm{Ni} \mathrm{(acac})_{2}(10 \mathrm{~mol} \%)$ 1,10
Equiv) Equiv)

DBU (2 equiv.), DMSO, $90^{\circ} \mathrm{C}, 12 \mathrm{~h}$<smiles>Ic1ccccc1</smiles>

Pd-CNT (5 mol\%)

Pd@PS (3 mol\%)<smiles>Ic1ccccc1</smiles><smiles>Ic1ccccc1</smiles>

Cu-DF@ ASMNP
$\mathrm{DBU}$ (3 equiv), DMF, $110^{\circ} \mathrm{C}, 12 \mathrm{~h}$

$\mathrm{Cs}_{2} \mathrm{CO}_{3}$, toluene, $100^{\circ} \mathrm{C}, 12 \mathrm{~h}$
95

Pyo et al. (2013)

66

dy et al. (2016)

92 This work

${ }^{a}$ Heterogeneous catalyst.

iodoarene and excellent yields were obtained for various internal alkynes. For $p$-iodotoluene and $p$-iodoanisole the yield was similar, 90 and $88 \%$ respectively (entries 2 and 3 ). However, slight increase in yield was obtained when haloarene bearing electron withdrawing substituent was employed (entry 5).

To gauge the efficacy of reaction, more practical coupling partner aryl bromides were used. To our delight they also worked very well for this coupling reaction and both electron withdrawing as well as electron donating aryl bromides were efficiently converted into corresponding internal alkynes in excellent yields. To further assess the potential of the catalyst, an aliphatic alkynoic acid, 2-butynoic acid (entry 11) was tested for this reaction but this afforded slightly lower yield. Isolated yields were obtained for few selected reactions consisting of haloarene bearing electron donating group (entry 3), neutral group (entry 4), a halogen substituent (entry 6) to check for any kind of interference, and electron withdrawing group (entry 10).

\subsubsection{Catalytic Stability and Reusability}

To test the reusability of catalyst, after each experiment (conducted under optimized conditions), the catalyst was magnetically separated, washed with ethyl acetate and ethanol 
and dried under vacuum. This was then used to perform subsequent reactions. It was observed that the catalyst was active up to seven runs without any notable decrease in its performance (Figure 8). SEM and TEM images further confirmed the unaltered structure and morphology of the recovered catalyst (Figure 3D and Figure 4F).

\subsubsection{Heterogeneity Test}

In order to estimate the leaching rate and heterogeneous nature of the catalyst, two sets of corresponding experiments were conducted. A standard reaction was conducted for the first set where the catalyst was magnetically removed after completion of reaction, and filtrate was analyzed under ICP, which showed no leaching. A split test was performed with the second set, in which the standard reaction was conducted with catalyst for 2 hours, which roughly corresponds to $20 \%$ conversion by GC-MS. Afterwards, the nanocatalyst was magentically separated from the reaction mixture and the reaction was further pursued. No coupling product in the reaction mixture was observed up to 10 hours under the same reaction conditions, which authenticate the truly heterogeneous nature of the nanocatalyst.

\subsubsection{Plausible Mechanism}

Figure 9 depicts the proposed mechanism that has been derived from earlier reports. (Okuro et al., 1993; Ray et al., 2008; Gonda et al., 2010; Lauterbach et al., 2010). The reaction between $\mathrm{Cu}-$ DF@ASMNPs A and alkynoic acid produces intermediate B, which undergoes decarboxylation to yield $\mathrm{C}$, an alkynyl copper intermediate. Further addition of haloarene results in the formation of another intermediate $\mathrm{D}$, which then undergoes reductive elimination, to give the product while regenerating the catalyst A.

Finally, in order to show the superiority of the synthesized catalyst, we compared our obtained results with the previously reported work (Table 2) and found that our catalyst was far more efficient in terms of reaction conditions, reaction time and catalytic recovery. Also, it is the first copper based heterogeneous system for synthesis of internal alkynes.

In summary, a highly effective palladium-free Cu-DF@ ASMNPs nanocatalyst was fabricated successfully and applied

\section{REFERENCES}

Abu-Reziq, R., and Alper, H. (2012). Magnetically Separable Base Catalysts: Heterogeneous Catalysis vs. Quasi-Homogeneous Catalysis. Appl. Sci. 2 (2), 260-276. doi:10.3390/app2020260

Abu-Reziq, R., Alper, H., Wang, D., and Post, M. L. (2006). Metal Supported on Dendronized Magnetic Nanoparticles: Highly Selective Hydroformylation Catalysts. J. Am. Chem. Soc. 128 (15), 5279-5282. doi: $10.1021 / \mathrm{ja} 060140 \mathrm{u}$

Arora, G., Yadav, M., Gaur, R., Gupta, R., and Sharma, R. K. (2017). A Novel and Template-free Synthesis of Multifunctional Double-Shelled Fe3 O4 -C Nanoreactor as an Ideal Support for Confined Catalytic Reactions. ChemistrySelect 2 (33), 10871-10879. doi:10.1002/slct.201701765

Brandsma, L. (2003). Best Synthetic Methods: Acetylenes, Allenes and Cumulenes. Elsevier. towards the synthesis of internal alkynes via decarboxylative cross-coupling reaction. These nanocomposites endowed low metal loading, high stability, and good functional group tolerance with excellent yields and high turn-over numbers. It is noteworthy that this catalytic system is the first report of copper based magnetic nanocatalyst that represents a practical and lowcost route to prepare internal alkynes. In addition, the effortless magnetic recovery and reusability of the catalyst for at least seven runs without any marked loss in its performance makes it an efficient protocol to produce a wide variety of unsymmetrical alkynes.

\section{DATA AVAILABILITY STATEMENT}

The original contributions presented in the study are included in the article/Supplementary Material, further inquiries can be directed to the corresponding author.

\section{AUTHOR CONTRIBUTIONS}

MY conceived the original idea. MY carried out the experiment and wrote the manuscript with support from AS, RG, RG, GA, and RS supervised the work.

\section{ACKNOWLEDGMENTS}

One of the authors MY thanks USIC, University of Delhi, Delhi, India, for providing instrumentation facilities. MY is immensely grateful to ACS GCI for recognizing part of this work as best poster at the 21st Green Chemistry and Engineering Conference in Reston, VA.

\section{SUPPLEMENTARY MATERIAL}

The Supplementary Material for this article can be found online at: https://www.frontiersin.org/articles/10.3389/fchem.2021.773855/ full\#supplementary-material

Chinchilla, R., and Nájera, C. (2007). The Sonogashira Reaction: a Booming Methodology in Synthetic Organic Chemistry. Chem. Rev. 107 (3), 874-922. doi: $10.1021 /$ cr050992x

Das, J. P., Roy, U. K., and Roy, S. (2005). Synthesis of Alkynyl and Vinyl Selenides via Selenodecarboxylation of Arylpropiolic and Cinnamic Acids. Organometallics 24 (25), 6136-6140. doi:10.1021/om050504b

Digigow, R. G., Dechézelles, J.-F., Dietsch, H., Geissbühler, I., Vanhecke, D., Geers, C., et al. (2014). Preparation and Characterization of Functional Silica Hybrid Magnetic Nanoparticles. J. Magnetism Magn. Mater. 362, 72-79. doi:10.1016/ j.jmmm.2014.03.026

Edwin Raja, G. C., Irudayanathan, F. M., Kim, H.-S., Kim, J., and Lee, S. (2016). Nickel-Catalyzed Hiyama-type Decarboxylative Coupling of Propiolic Acids and Organosilanes. J. Org. Chem. 81, 5244-5249. doi:10.1021/acs.joc.6b00883

Esmaeilpour, M., Sardarian, A. R., and Javidi, J. (2012). Schiff Base Complex of Metal Ions Supported on Superparamagnetic Fe3O4@SiO2 Nanoparticles: An Efficient, Selective and Recyclable Catalyst for Synthesis of 1,1-diacetates from 
Aldehydes under Solvent-free Conditions. Appl. Catal. A: Gen. 445-446, 359-367. doi:10.1016/j.apcata.2012.09.010

Evano, G., Blanchard, N., and Toumi, M. (2008). Copper-mediated Coupling Reactions and Their Applications in Natural Products and Designed Biomolecules Synthesis. Chem. Rev. 108 (8), 3054-3131. doi:10.1021/cr8002505

Feng, C., and Loh, T.-P. (2010). Palladium-catalyzed Decarboxylative CrossCoupling of Alkynyl Carboxylic Acids with Arylboronic Acids. Chem. Commun. 46 (26), 4779-4781. doi:10.1039/c0cc00403k

Gonda, Z., Tolnai, G. L., and Novák, Z. (2010). Dramatic Impact of Ppb Levels of Palladium on the "Copper-Catalyzed" Sonogashira Coupling. Chem. - A Eur. J. 16 (39), 11822-11826. doi:10.1002/chem.201001880

Gupta, R., Yadav, M., Gaur, R., Arora, G., and Sharma, R. K. (2017). A Straightforward One-Pot Synthesis of Bioactive N-Aryl Oxazolidin-2Ones via a Highly Efficient Fe3O4@SiO2-Supported Acetate-Based Butylimidazolium Ionic Liquid Nanocatalyst under Metal- and Solvent-free Conditions. Green. Chem. 19 (16), 3801-3812. doi: $10.1039 / \mathrm{c} 7 \mathrm{gc} 01414 \mathrm{~g}$

Hu, A., Yee, G. T., and Lin, W. (2005). Magnetically Recoverable Chiral Catalysts Immobilized on Magnetite Nanoparticles for Asymmetric Hydrogenation of Aromatic Ketones. J. Am. Chem. Soc. 127 (36), 12486-12487. doi:10.1021/ ja053881o

Jia, W., and Jiao, N. (2010). Cu-catalyzed Oxidative Amidation of Propiolic Acids under Air via Decarboxylative Coupling. Org. Lett. 12 (9), 2000-2003. doi:10.1021/ol1004615

Jutand, A. (2004). Dual Role of Nucleophiles in Palladium-Catalyzed Heck, Stille, and Sonogashira Reactions. Pure Appl. Chem. 76 (3), 565-576. doi:10.1351/ pac200476030565

Kim, H., and Lee, P. H. (2009). Palladium-Catalyzed Decarboxylativesp-sp2CrossCoupling Reactions of Aryl and Vinyl Halides and Triflates with $\hat{\mathrm{I}}+, \hat{\mathrm{I}}^{2}$-Ynoic Acids Using Silver Oxide. Adv. Synth. Catal. 351 (17), 2827-2832. doi:10.1002/ adsc. 200900502

Kolarovic, A., Schnürch, M., and Mihovilovic, M. D. (2011). Tandem Catalysis: from Alkynoic Acids and Aryl Iodides to 1, 2, 3-triazoles in One Pot. J. Org. Chem. 76 (8), 2613-2618.

Kooti, M., and Afshari, M. (2012). Phosphotungstic Acid Supported on Magnetic Nanoparticles as an Efficient Reusable Catalyst for Epoxidation of Alkenes. Mater. Res. Bull. 47 (11), 3473-3478. doi:10.1016/j.materresbull.2012.07.001

Lauterbach, T., Livendahl, M., Rosellón, A., Espinet, P., and Echavarren, A. M. (2010). Unlikeliness of Pd-free Gold(I)-Catalyzed Sonogashira Coupling Reactions. Org. Lett. 12 (13), 3006-3009. doi:10.1021/ol101012n

Lee, J.-H., Raja, G. C. E., Son, Y., Jang, J., Kim, J., and Lee, S. (2016). Nickelcatalyzed Oxidative Decarboxylative Coupling Reactions between Alkynyl Carboxylic Acids and Arylboronic Acids. Tetrahedron Lett. 57 (43), 4824-4828. doi:10.1016/j.tetlet.2016.09.054

Ley, S. V., and Thomas, A. W. (2003). Modern Synthetic Methods for CopperMediated C(aryl)O, C(aryl)N, and C(aryl)S Bond Formation. Angew. Chem. Int. Ed. 42 (44), 5400-5449. doi:10.1002/anie.200300594

Li, T., Qu, X., Zhu, Y., Sun, P., Yang, H., Shan, Y., et al. (2011). Synthesis of Diarylalkynes by Iron/Copper Co-Catalyzed Decarboxylative Sp Sp2 Coupling of Alkynyl Carboxylic Acids and Aryl Halides. Adv. Syn. Catal. 353 (14-15), 2731-2738. doi:10.1002/adsc.201100238

Li, T., Sun, P., Yang, H., Zhu, Y., Yan, H., Lu, L., et al. (2012). Copper-catalyzed Decarboxylative Coupling of Aryl Halides with Alkynyl Carboxylic Acids Performed in Water. Tetrahedron 68 (32), 6413-6419. doi:10.1016/j.tet.2012.06.003

Li, X., Yang, F., and Wu, Y. (2013). Palladacycle-Catalyzed Decarboxylative Coupling of Alkynyl Carboxylic Acids with Aryl Chlorides under Air. J. Org. Chem. 78 (9), 4543-4550. doi:10.1021/jo400574d

Maaliki, C., Chevalier, Y., Thiery, E., and Thibonnet, J. (2016). Palladium and Copper Catalyzed Sonogashira Decarboxylative Coupling of Aryl Iodides and Alkynyl Carboxylic Acids. Tetrahedron Lett. 57 (30), 3358-3362. doi:10.1016/ j.tetlet.2016.06.073

Masteri-Farahani, M., and Tayyebi, N. (2011). A New Magnetically Recoverable Nanocatalyst for Epoxidation of Olefins. J. Mol. Catal. A. Chem. 348 (1), 83-87. doi:10.1016/j.molcata.2011.08.007

Monnier, F., and Taillefer, M. (2009). Catalytic CC, CN, and CO Ullmann-type Coupling Reactions. Angew. Chem. Int. Ed. 48 (38), 6954-6971. doi:10.1002/ anie.200804497
Moon, J., Jang, M., and Lee, S. (2008a). Palladium-catalyzed Decarboxylative Coupling of Alkynyl Carboxylic Acids and Aryl Halides. J. Org. Chem. 74 (3), 1403-1406. doi:10.1021/jo802290r

Moon, J., Jeong, M., Nam, H., Ju, J., Moon, J. H., Jung, H. M., et al. (2008b). OnePot Synthesis of Diarylalkynes Using Palladium-Catalyzed Sonogashira Reaction and Decarboxylative Coupling of Sp Carbon and Sp2 Carbon. Org. Lett. 10 (5), 945-948. doi:10.1021/ol703130y

Negishi, E.-i., and Anastasia, L. (2003). Palladium-catalyzed Alkynylation. Chem. Rev. 103 (5), 1979-2018. doi:10.1021/cr020377i

Nicolaou, K. C., Bulger, P. G., and Sarlah, D. (2005). Palladium-Catalyzed CrossCoupling Reactions in Total Synthesis. Angew. Chem. Int. Ed. 44 (29), 4442-4489. doi:10.1002/anie.200500368

Okuro, K., Furuune, M., Enna, M., Miura, M., and Nomura, M. (1993). Synthesis of Aryl- and Vinylacetylene Derivatives by Copper-Catalyzed Reaction of Aryl and Vinyl Iodides with Terminal Alkynes. J. Org. Chem. 58 (17), 4716-4721. doi:10.1021/jo00069a040

Pan, D., Zhang, C., Ding, S., and Jiao, N. (2011). Phosphane-Free CopperCatalyzed Decarboxylative Coupling of Alkynyl Carboxylic Acids with Aryl Halides under Aerobic Conditions. Eur. J. Org. Chem. 2011 (25), 4751-4755. doi:10.1002/ejoc.201101187

Park, A., Park, K., Kim, Y., and Lee, S. (2011). Pd-catalyzed Carbonylative Reactions of Aryl Iodides and Alkynyl Carboxylic Acids via Decarboxylative Couplings. Org. Lett. 13 (5), 944-947. doi:10.1021/ol102993y

Park, K., Bae, G., Moon, J., Choe, J., Song, K. H., and Lee, S. (2010). Synthesis of Symmetrical and Unsymmetrical Diarylalkynes from Propiolic Acid Using Palladium-Catalyzed Decarboxylative Coupling. J. Org. Chem. 75 (18), 6244-6251. doi:10.1021/jo101398a

Park, K., and Lee, S. (2013). Transition Metal-Catalyzed Decarboxylative Coupling Reactions of Alkynyl Carboxylic Acids. RSC Adv. 3 (34), 14165-14182. doi:10.1039/c3ra41442f

Polshettiwar, V., and Varma, R. S. (2009). Nanoparticle-supported and Magnetically Recoverable Palladium (Pd) Catalyst: a Selective and Sustainable Oxidation Protocol with High Turnover Number. Org. Biomol. Chem. 7 (1), 37-40. doi:10.1039/b817669h

Pyo, A., Kim, J. D., Choi, H. C., and Lee, S. (2013). Ligand-free PalladiumCatalyzed Decarboxylative Coupling Reactions of Aryl Iodides and Alkynyl Carboxylic Acids. J. Organomet. Chem. 724, 271-274. doi:10.1016/ j.jorganchem.2012.11.029

Qu, X., Li, T., Sun, P., Zhu, Y., Yang, H., and Mao, J. (2011). Highly Effective Copper-Catalyzed Decarboxylative Coupling of Aryl Halides with Alkynyl Carboxylic Acids. Org. Biomol. Chem. 9 (20), 6938-6942. doi:10.1039/ clob05969f

Ray, L., Barman, S., Shaikh, M. M., and Ghosh, P. (2008). Highly Convenient Amine-free Sonogashira Coupling in Air in a Polar Mixed Aqueous Medium Bytrans- andcis-[(NHC)2PdX2] $(\mathrm{X}=\mathrm{Cl}, \mathrm{Br})$ Complexes ofN/O-Functionalized N-Heterocyclic Carbenes. Chem. Eur. J. 14 (22), 6646-6655. doi:10.1002/ chem. 200800301

Reddy, C. B., Bharti, R., Kumar, S., and Das, P. (2016). Supported Palladium Nanoparticles-Catalyzed Decarboxylative Coupling Approaches to Aryl Alkynes, Indoles and Pyrrolines Synthesis. RSC Adv. 6 (75), 71117-71121. doi:10.1039/c6ra12046f

Reddy, P. V., Srinivas, P., Annapurna, M., Bhargava, S., Wagler, J., Mirzadeh, N., et al. (2013). Phosphine-Free Palladium-Catalyzed Decarboxylative Coupling of Alkynylcarboxylic Acids with Aryl and Heteroaryl Halides. Adv. Synth. Catal. 355 (4), 705-710. doi:10.1002/adsc.201200876

Rossi, L. M., Costa, N. J. S., Silva, F. P., and Wojcieszak, R. (2014). Magnetic Nanomaterials in Catalysis: Advanced Catalysts for Magnetic Separation and beyond. Green. Chem. 16 (6), 2906-2933. doi:10.1039/c4gc00164h

Shang, R., Fu, Y., Wang, Y., Xu, Q., Yu, H.-Z., and Liu, L. (2009). Copper-Catalyzed Decarboxylative Cross-Coupling of Potassium Polyfluorobenzoates with Aryl Iodides and Bromides. Angew. Chem. 121 (49), 9514-9518. doi:10.1002/ ange.200904916

Sharma, R. K., Gaur, R., Yadav, M., Goswami, A., Zbořil, R., and Gawande, M. B. (2018). An Efficient Copper-Based Magnetic Nanocatalyst for the Fixation of Carbon Dioxide at Atmospheric Pressure. Sci. Rep. 8 (1), 1901. doi:10.1038/ s41598-018-19551-3 
Sharma, R. K., Gaur, R., Yadav, M., Rathi, A. K., Pechousek, J., Petr, M., et al. (2015a). Maghemite-Copper Nanocomposites: Applications for Ligand-free Cross-Coupling (C-O, C-S, and C-N) Reactions. ChemCatChem. 7 (21), 3495-3502. doi:10.1002/cctc.201500546

Sharma, R. K., Yadav, M., Gaur, R., Gupta, R., Adholeya, A., and Gawande, M. B. (2016a). Synthesis of Iron Oxide Palladium Nanoparticles and Their Catalytic Applications for Direct Coupling of Acyl Chlorides with Alkynes. ChemPlusChem. 81 (12), 1312-1319. doi:10.1002/cplu.201600321

Sharma, R. K., Yadav, M., Gaur, R., Monga, Y., and Adholeya, A. (2015b). Magnetically Retrievable Silica-Based Nickel Nanocatalyst for SuzukiMiyaura Cross-Coupling Reaction. Catal. Sci. Technol. 5 (5), 2728-2740. doi:10.1039/c4cy01736f

Sharma, R. K., Yadav, M., and Gawande, M. B. (2016b). "Silica-coated Magnetic Nano-Particles: Application in Catalysis," in Ferrites and Ferrates: Chemistry and Applications in Sustainable Energy and Environmental Remediation (ACS Publications), 1-38. doi:10.1021/bk-2016-1238.ch001

Sharma, R. K., Yadav, M., Monga, Y., Gaur, R., Adholeya, A., Zboril, R., et al. (2016c). Silica-Based Magnetic Manganese Nanocatalyst - Applications in the Oxidation of Organic Halides and Alcohols. ACS Sustain. Chem. Eng. 4 (3), 1123-1130. doi:10.1021/acssuschemeng.5b01183

Siemsen, P., Livingston, R. C., and Diederich, F. (2000). Acetylenic Coupling: a Powerful Tool in Molecular Construction. Angew. Chem. Int. Ed. 39 (15), 2632-2657. anie2632>3.0.co;2-f

Sonogashira, K. (2002). Development of Pd-Cu Catalyzed Cross-Coupling of Terminal Acetylenes with Sp2-Carbon Halides. J. Organomet. Chem. 653 (12), 46-49. doi:10.1016/s0022-328x(02)01158-0

Stang, P. J. (2008). Metal-catalyzed Cross-Coupling Reactions. John Wiley \& Sons.

Stang, P. J., and Tykwinski, R. R. (2006). Acetylene Chemistry: Chemistry, Biology and Material Science. John Wiley \& Sons.

Tartaggia, S., De Lucchi, O., and Gooßen, L. J. (2012). Practical Synthesis of Unsymmetrical Diarylacetylenes from Propiolic Acid and Two Different Aryl Bromides. Eur. J. Org. Chem. 2012 (7), 1431-1438. doi:10.1002/ejoc.201101770

Tykwinski, R. R. (2003). Evolution in the Palladium-Catalyzed Cross-Coupling of Sp- and Sp2-Hybridized Carbon Atoms. Angew. Chem. Int. Ed. 42 (14), 1566-1568. doi:10.1002/anie.200201617

Wang, D., and Astruc, D. (2014). Fast-Growing Field of Magnetically Recyclable Nanocatalysts. Chem. Rev. 114 (14), 6949-6985. doi:10.1021/cr500134h

Wang, J., Zheng, S., Shao, Y., Liu, J., Xu, Z., and Zhu, D. (2010). Aminofunctionalized Fe3O4@SiO2 Core-Shell Magnetic Nanomaterial as a Novel Adsorbent for Aqueous Heavy Metals Removal. J. Colloid Interf. Sci. 349 (1), 293-299. doi:10.1016/j.jcis.2010.05.010

Wang, S., Zhang, Z., Liu, B., and Li, J. (2013). Silica Coated Magnetic Fe3O4 Nanoparticles Supported Phosphotungstic Acid: a Novel Environmentally Friendly Catalyst for the Synthesis of 5-ethoxymethylfurfural from 5- hydroxymethylfurfural and Fructose. Catal. Sci. Technol. 3 (8), 2104-2112. doi: $10.1039 /$ c3cy00223c

Wang, Z., Wang, X., Sun, H., Zhu, Z., Zhang, G., Zhang, W., et al. (2016). TriazineTriazole Conjugates as Potent Ligands for Cu-Catalyzed Sonogashira Reaction. ChemistrySelect 1 (3), 391-395. doi:10.1002/slct.201600113

Yamaura, M., Camilo, R., Sampaio, L., Macedo, M., Nakamura, M., and Toma, H. (2004). Preparation and Characterization of (3-aminopropyl) TriethoxysilaneCoated Magnetite Nanoparticles. J. Magn. Magn. Mater. 279 (2), 210-217. doi:10.1016/j.jmmm.2004.01.094

Zhang, Q., Su, H., Luo, J., and Wei, Y. (2012). A Magnetic Nanoparticle Supported Dual Acidic Ionic Liquid: a "Quasi-Homogeneous" Catalyst for the One-Pot Synthesis of Benzoxanthenes. Green. Chem. 14 (1), 201-208. doi:10.1039/c1gc16031a

Zhang, W.-W., Zhang, X.-G., and Li, J.-H. (2010). Palladium-catalyzed Decarboxylative Coupling of Alkynyl Carboxylic Acids with Benzyl Halides or Aryl Halides. J. Org. Chem. 75 (15), 5259-5264. doi:10.1021/jo1010284

Zhang, Z., Zhang, F., Zhu, Q., Zhao, W., Ma, B., and Ding, Y. (2011). Magnetically Separable Polyoxometalate Catalyst for the Oxidation of Dibenzothiophene with H2O2. J. Colloid Interf. Sci. 360 (1), 189-194. doi:10.1016/ j.jcis.2011.04.045

Zhao, D., Gao, C., Su, X., He, Y., You, J., and Xue, Y. (2010). Coppercatalyzed Decarboxylative Cross-Coupling of Alkynyl Carboxylic Acids with Aryl Halides. Chem. Commun. 46 (47), 9049-9051. doi:10.1039/ c0cc03772a

Zhu, J., He, J., Du, X., Lu, R., Huang, L., and Ge, X. (2011). A Facile and Flexible Process of $\beta$-cyclodextrin Grafted on Fe3O4 Magnetic Nanoparticles and HostGuest Inclusion Studies. Appl. Surf. Sci. 257 (21), 9056-9062. doi:10.1016/ j.apsusc.2011.05.099

Conflict of Interest: The authors declare that the research was conducted in the absence of any commercial or financial relationships that could be construed as a potential conflict of interest.

Publisher's Note: All claims expressed in this article are solely those of the authors and do not necessarily represent those of their affiliated organizations, or those of the publisher, the editors and the reviewers. Any product that may be evaluated in this article, or claim that may be made by its manufacturer, is not guaranteed or endorsed by the publisher.

Copyright (C) 2022 Yadav, Srivastava, Gaur, Gupta, Arora and Sharma. This is an open-access article distributed under the terms of the Creative Commons Attribution License (CC BY). The use, distribution or reproduction in other forums is permitted, provided the original author(s) and the copyright owner(s) are credited and that the original publication in this journal is cited, in accordance with accepted academic practice. No use, distribution or reproduction is permitted which does not comply with these terms. 